\title{
Clinical manifestations, imaging features, and endoscopic management of renal pseudocysts: a case series
}

\author{
Surinder Singh Rana ${ }^{a}$, Saurabh Dawra ${ }^{a}$, Ravi Sharmaa, Mandeep Kang ${ }^{b}$, Rajesh Gupta \\ Postgraduate Institute of Medical Education and Research (PGIMER), Chandigarh, India
}

Abstract

Background Renal pseudocysts (RP) are rare and we know little about their presentation and management. In the present case series, we present the pertinent clinico-radiological features as well as the role of endoscopic drainage in symptomatic RP.

Methods A retrospective analysis was performed of patients with RP seen in our unit over the last 12 years. Patient symptoms, imaging findings and details of endoscopic or endoscopic ultrasound (EUS)-guided drainage procedures were evaluated.

Results Eight patients with RP (7 male; mean age: 33.1 years) were studied. Seven patients had underlying chronic pancreatitis (calcific in 3), predominantly alcohol-related. The mean size of the $\mathrm{RP}$ was $8.5 \mathrm{~cm}$. All patients presented with abdominal pain and none had urinary complaints. The RP could be well detected on both contrast-enhanced computed tomography and EUS. None of the patients had significant debris on EUS. Five patients were treated with combined transmural and transpapillary drainage, 2 patients were treated with transpapillary drainage alone, while combined percutaneous and transpapillary drainage was performed in 1 patient. All patients had partial disruption of the main pancreatic duct and a bridging transpapillary endoprosthesis was successfully placed. The RP resolved in all patients within 2-6 weeks and no patient required surgery. There were no complications and no patient had recurrence of RP over a follow-up period of 3-118 months.

Conclusion RP are usually associated with abdominal pain and do not cause renal symptoms. Endoscopic drainage is a safe and effective minimally invasive management option for RP.

Keywords Pseudocyst, endosonography, stent, chronic pancreatitis, acute pancreatitis

Ann Gastroenterol 2020; 33 (3): 1-5

\section{Introduction}

Pancreatic pseudocyst is a circumscribed and encapsulated fluid collection surrounded by a non-epithelial wall of fibrous or granulation tissue. It occurs as a result of acute pancreatitis, chronic pancreatitis or traumatic pancreatitis [1]. The pseudocysts are usually located in the peripancreatic region. Pseudocysts can also occur at atypical locations, including

Department of a Gastroenterology (Surinder Singh Rana, Saurabh

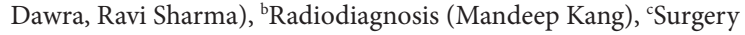
(Rajesh Gupta), Postgraduate Institute of Medical Education and Research (PGIMER), Chandigarh, India

Conflict of Interest: None

Correspondence to: Dr Surinder Singh Rana, Professor, Department of Gastroenterology, PGIMER, Chandigarh, 160012 India,

e-mail: drsurinderrana@gmail.com

Received 19 November 2019; accepted 4 March 2020;

published online 3 April 2020

DOI: https://doi.org/10.20524/aog.2020.0476 liver, spleen, mediastinum, pelvis and kidney [2-6]. There is paucity of published literature on the clinical and radiological features, or the management of pseudocysts of pancreas at atypical locations. Hence, their diagnosis and management is a challenge. In our previously published case series, we have described the role of endoscopic treatment of hepatic, mediastinal as well as splenic pseudocysts [2-4,6].

Renal pseudocysts (RP) occur rarely and have been mentioned in the literature only as case reports [7-13]. There is paucity of literature on the clinical manifestations and radiological findings in patients with RP. The management of pancreatic RP is also debatable. Percutaneous drainage or surgery has been described as a treatment modality in the literature [8-10]. With the advent of minimally invasive endoscopic transpapillary as well as transmural drainage, there have been reports of successful treatment of pancreatic pseudocysts at atypical locations [2,6,14]. Endoscopic and endoscopic ultrasound (EUS)-guided drainage of RP have also been described but the experience is limited to a few case reports $[7,13]$. In the current case series, we present the clinicoradiological features of 8 patients with RP seen in our unit over 
the last 12 years. We also evaluated the safety and efficacy of endoscopic drainage in the management of patients with renal pancreatic pseudocysts.

\section{Patients and methods}

This retrospective study was conducted in a pancreatology unit of a large tertiary care hospital in north India. The database of patients with pancreatic pseudocysts at atypical locations seen over the last 12 years was searched to identify patients with RP. RP was defined as fluid collection secondary to pancreatitis occurring in the subcapsular location in either the right or the left kidney. The database was maintained prospectively. The clinical manifestations and imaging details, along with the EUS findings, were retrieved from the database, together with the details of management, including endoscopic drainage and its outcome, as well as complications, if any. All the endoscopic procedures were performed after informed consent had been obtained from the patients.

All patients were symptomatic and RP was documented on abdominal ultrasound as well as contrast-enhanced computed tomography (CECT). After EUS became available at our center from 2008 onwards, the RP were also evaluated with radial EUS. EUS was performed using a radial echoendoscope (EG3670 URK radial echoendoscope, Pentax Corp., Japan, or GFUE 160 radial echoendoscope, Olympus Corp., Japan) at a frequency of 7.5 MHz. EUS was performed in the left lateral decubitus position under conscious sedation using intravenous midazolam $(2.5-5 \mathrm{mg})$. On EUS the echo pattern of the pancreas was evaluated and the presence of ascites or pleural effusion, as well as any other peripancreatic collection, was also noted. The RP was evaluated from the stomach and its size and detailed morphology were observed, with special emphasis on the presence or absence of solid necrotic debris.

All the patients with symptomatic RP were treated with attempted endoscopic drainage. In the initial period of the study (before 2008), when EUS was not available at our center, the patients were treated with endoscopic transpapillary drainage. After the availability of EUS, all patients were initially treated with EUS-guided transmural drainage, followed by endoscopic transpapillary drainage, if required. The endoscopic drainage was done under conscious sedation using intravenous midazolam and antibiotic prophylaxis using intravenous ciprofloxacin. The antibiotic was continued orally for 5 days.

\section{Endoscopic transpapillary drainage}

Endoscopic retrograde cholangiopancreatography was performed using a TJF 145 or TJF 160 (Olympus Optical Co. Ltd., Tokyo Japan) side viewing duodenoscope. After selective cannulation of the pancreatic duct, a minimal amount of contrast was injected to confirm duct disruption, defined as extravasation of contrast outside the ductal system, as visualized on fluoroscopy. Complete pancreatic duct disruption was noted when the main duct upstream of the disruption could not be visualized, and partial disruption when the main duct upstream of the disruption was visualized. After the duct disruption had been confirmed, a 5/7-Fr plastic endoprosthesis was placed into the pancreatic duct in order to bridge the site of duct disruption.

\section{EUS-guided transmural drainage}

EUS-guided drainage was done using an echoendoscope (EG-3870 UTK linear echoendoscope Pentax Inc., Tokyo, Japan, or GF-UCT 180 linear echoendoscope, Olympus Optical Co. Ltd., Tokyo Japan) under fluoroscopic guidance. Depending upon the distance between the stomach and the renal pseudocyst, either EUS-guided single-time aspiration, or EUS-guided transmural drainage using a single 7-Fr double pigtail plastic stent was performed. The optimal site for drainage/aspiration of the RP was chosen under EUS and color Doppler guidance, ensuring a minimal distance between the pancreatic fluid collection and the gastroduodenal lumen, as well as avoiding any intervening blood vessels. Once the site of puncture was confirmed, a 19-G needle was used to make the initial puncture. The fluid was aspirated and sent for microbiological and biochemical analysis. If the distance between the cyst wall and the gastric lumen was more than $1 \mathrm{~cm}$, single-time complete aspiration of the cyst was performed. However, if the distance was less than $1 \mathrm{~cm}$, a single 7-Fr 5-cm double pigtail transmural stent was placed. The stent was placed after dilation of the tract with either a non-cautery method using an endoscopic retrograde pancreatography (ERP) cannula or a $4 \mathrm{~mm}$ biliary balloon dilator, or by electrocautery using a 6-Fr cystotome (Cysto Gastro Set; Endoflex, GmbH, Voerde, Germany) after placement of a $0.025 \% / 0.035$ " guidewire. If the contents were thick or the cyst was $>6 \mathrm{~cm}$ in size, the transmural tract was further dilated up to $12 \mathrm{~mm}$ using a wire-guided hydrostatic balloon.

\section{Follow up}

All patients were followed-up at 2-weekly intervals. On follow up, the following parameters were recorded: clinical resolution/worsening of symptoms, occurrence of fever, or any other new symptoms. An abdominal ultrasound was performed in all patients at 2-weekly intervals until resolution of the RP, confirmed by abdominal CECT. After resolution of the RP, ERP was performed to demonstrate duct disruption in patients who had initially undergone transmural drainage.

In patients with partial duct disruption, a transpapillary bridging stent was placed, whereas no transpapillary stent was placed in patients with complete disruption. Patients with partial duct disruption had both the transpapillary and transmural stents removed after the healing of ductal disruption had been documented on ERP, whereas in patients with complete duct disruption the transmural stent was removed after 8 weeks. 


\section{Outcome definitions}

Treatment success was defined as resolution of symptoms with resolution of RP on CT with no need for surgery. Need for surgery for resolution or any complication of endoscopic drainage was considered as treatment failure. Any complications that occurred following endoscopic drainage were also retrieved, together with their outcomes.

\section{Results}

Eight patients with RP, 7 male, mean age $33.1 \pm 8.2$ years (range 22-42) were studied (Table 1). Seven patients had underlying chronic pancreatitis (calcific in 3 patients), while 1 patient developed RP consequent to idiopathic acute pancreatitis. The majority of patients $(5 / 8 ; 62.5 \%)$ had alcoholrelated chronic pancreatitis, while 2 patients $(2 / 8 ; 25 \%)$ had idiopathic chronic pancreatitis. The presenting complaint in all the patients was abdominal pain. The pain was localized in the upper abdomen in 5 patients, and 3 patients with a large $\mathrm{RP}(12 \mathrm{~cm}, 14 \mathrm{~cm}$ and $15 \mathrm{~cm})$ had pain localized to the left loin. None of the patients had any urinary symptoms and on evaluation renal functions were normal in all patients. The urine biochemical examinations, including amylase values, were normal in all patients. In addition, blood and urine cultures were sterile in all patients. Only 1 patient had a coexisting peripancreatic pseudocyst. The mean size of the RP was $8.5 \pm 4.3 \mathrm{~cm}$, with the largest being $15 \mathrm{~cm}$ in diameter. In all the patients, the RP could be well documented on abdominal
CECT and appeared as subcapsular cystic lesions involving the left kidney in all the 8 patients. The renal perfusion, as documented on contrast enhancement during CT, was similar in both the kidneys in all the 8 studied patients.

EUS was applied in 5 patients and RP could be well visualized on EUS. None of these 5 patients had significant solid debris on EUS. Of 7 patients with chronic pancreatitis, EUS was able to document communication of the main pancreatic duct with the RP in 3 (42\%). Endoscopic transpapillary drainage alone was performed in 2 patients using a 7-Fr stent and a 5-Fr nasopancreatic drain, respectively. Both these patients had partial duct disruption at the tail end of the pancreas and the endoprosthesis bridged the disruption. One patient initially underwent percutaneous drainage of the RP at another healthcare facility and was subsequently referred to us for pancreatic endotherapy. On ERP, this patient had partial duct disruption at the tail end of the pancreas, bridged with a 7-Fr stent. Three patients were successfully treated with initial endoscopic transmural drainage followed by endoscopic transpapillary drainage (Fig. 1), whereas 2 patients underwent initial single-time aspiration of the RP followed by placement of a bridging transpapillary stent. In all the patients who underwent EUSguided aspiration or transmural drainage, the fluid amylase levels were markedly elevated (1600 IU/L to $34,500 \mathrm{IU} / \mathrm{L}$ ). There were no complications of these various endoscopic interventional procedures.

The RP resolved in all the patients within a mean period of $3.8 \pm 1.4$ weeks (range 2-6) and none of the patients required surgical management. There has been no recurrence of RP over a mean follow-up period of 52.3 \pm 38.2 months (range 3-118).

Table 1 Clinical profile and outcome after endoscopic drainage in patients with renal pseudocysts

\begin{tabular}{|c|c|c|c|c|c|c|c|c|c|c|c|}
\hline S.No & Age & Sex & Etiology & Pain & $\begin{array}{l}\text { Size } \\
(\mathrm{cm})\end{array}$ & $\begin{array}{l}\text { Coexistent } \\
\text { pseudocyst }\end{array}$ & $\begin{array}{l}\text { Duct disruption } \\
\text { and location }\end{array}$ & $\begin{array}{c}\text { Transmural } \\
\text { drainage }\end{array}$ & $\begin{array}{c}\text { Transpapillary } \\
\text { drainage }\end{array}$ & $\begin{array}{c}\text { Period of } \\
\text { resolution(weeks) }\end{array}$ & $\begin{array}{c}\text { Follow up } \\
\text { (months) }\end{array}$ \\
\hline $1^{* * *}$ & 42 & $\mathrm{M}$ & Alcohol & Present & 7 & No & $\begin{array}{l}\text { Partial, single, } \\
\text { tail }\end{array}$ & $7 \mathrm{Fr} \times 5 \mathrm{~cm}$ & $5 \mathrm{Fr}$ & 4 & 42 \\
\hline 2 & 22 & M & Idiopathic & Present & 15 & No & $\begin{array}{l}\text { Partial, single, } \\
\text { tail }\end{array}$ & No & $7 \mathrm{Fr}$ & 6 & 102 \\
\hline 3 & 35 & M & Alcohol & Present & 12 & No & $\begin{array}{l}\text { Partial, single, } \\
\text { tail }\end{array}$ & $7 \mathrm{Fr} \times 5 \mathrm{~cm}$ & $7 \mathrm{Fr}$ & 2 & 3 \\
\hline 4 & 34 & M & Alcohol & Present & 6 & No & $\begin{array}{l}\text { Partial, single, } \\
\text { tail }\end{array}$ & $\begin{array}{l}\text { Single-time } \\
\text { aspiration }\end{array}$ & $7 \mathrm{Fr}$ & 2 & 72 \\
\hline 5 & 26 & M & Idiopathic & Present & 8 & No & $\begin{array}{l}\text { Partial, single, } \\
\text { tail }\end{array}$ & $\begin{array}{l}\text { Single-time } \\
\text { aspiration }\end{array}$ & $7 \mathrm{Fr}$ & 3 & 36 \\
\hline 6 & 42 & M & Alcohol & Present & 14 & No & $\begin{array}{l}\text { Partial, single, } \\
\text { tail }\end{array}$ & $\begin{array}{c}\text { No, additional } \\
\text { PCD }\end{array}$ & $7 \mathrm{Fr}$ & 4 & 23 \\
\hline $7^{* *}$ & 22 & F & $\begin{array}{l}\text { Idiopathic } \\
\text { acute }\end{array}$ & Present & $1.5^{*}$ & No & $\begin{array}{l}\text { Partial, single, } \\
\text { tail }\end{array}$ & No & 5 Fr NPD & 6 & 118 \\
\hline $8^{* *}$ & 42 & M & Alcohol & Present & 5 & Yes & $\begin{array}{l}\text { Partial, single, } \\
\text { tail }\end{array}$ & 7 Fr $5 \mathrm{~cm}$ & $5 \mathrm{Fr}$ & 4 & 23 \\
\hline
\end{tabular}



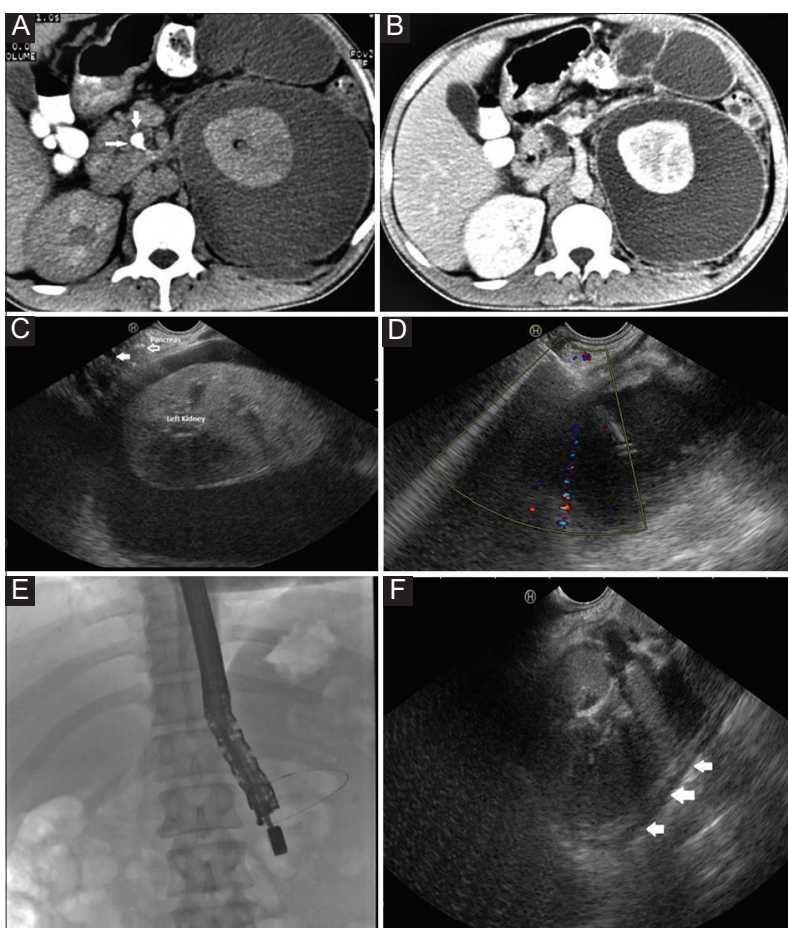

Figure 1 (A) Computed tomography (CT): parenchymal calcification in head of pancreas (arrow) and $12 \mathrm{~cm}$ subcapsular fluid collection encircling the left kidney. (B) Contrast-enhanced CT: The left kidney was compressed by the collection but cortical opacification on intravenous contrast was similar to the right kidney. (C) Endoscopic ultrasound (EUS): left-sided renal pseudocyst with echogenic foci (open arrow) and strands in the pancreatic parenchyma with dilated main pancreatic duct (bold arrow). (D) EUS-guided transmural drainage of pseudocyst. The pseudocyst punctured with a 19-G needle. (E) EUS-guided transmural drainage of pseudocyst. The guidewire coiled into the renal pseudocyst. (F) EUS at 2 weeks: Resolved renal pseudocyst with thin rim of fluid around the kidney (arrows)

\section{Discussion}

Pancreatic pseudocysts are known to extend beyond the confines of the peripancreatic space as a result of dissection along the fascial planes by enzyme-rich pancreatic juice. Pancreatic fluid collections have been reported to extrinsically compress the kidney, but extension of pancreatic pseudocysts into perirenal space is very rare and RP have only been described in the literature as case reports [7,9,11-13]. In this case series, we have described the clinical manifestations and imaging features, as well as the safety and efficacy of endoscopic management of RP. The RP are due to penetration of Gerota's fascia by pancreatic enzymes and subsequent digestion of perirenal fat/tissue by enzymes, leading on to formation of perirenal cystic collection [15].

RP more commonly affect the left kidney, as it has a close anatomic relation with the pancreas and the duodenum acts as an anatomical barrier to the spread of pancreatic juices to the right kidney $[14,15]$. In our study, all the 8 patients had involvement of the left kidney and none had RP on the right side. The clinical presentation of RP can be varied and has been reported as incidentally detected renal masses, or presenting with abdominal pain or complications such as perirenal abscess, obstructive hydronephrosis, pseudoaneurysm or reninmediated hypertension [8,15-17]. In our study, all the patients with RP presented with abdominal pain and all 3 patients with large RP also had loin pain. None of these patients had the above-described renal or vascular complications.

All patients with RP had normal renal function tests with normal urinary amylase values. The majority of reported cases of RP had normal renal function tests as well as routine urine examination. The RP were well documented on abdominal CECT and appeared as perirenal cystic lesions. The RP were also well visualized on EUS, which allowed a better evaluation of their contents. Additionally, EUS was able to demonstrate communication of the main pancreatic duct with the RP in $42 \%$ of the patients with chronic pancreatitis. In patients who present a diagnostic dilemma, cyst fluid can be aspirated and analyzed for fluid amylase values $[9,10,15]$. We did not perform diagnostic aspiration in any of our patients: either they had already been diagnosed with acute or chronic pancreatitis, or the imaging modality, including CECT, EUS and ERP, demonstrated underlying chronic pancreatitis or duct disruption with communication with the RP.

There are no definite guidelines to aid in the management of RP. They have traditionally been managed surgically or using image-guided percutaneous drainage $[8,10,15]$. There have been a few case reports of successful management of RP using transpapillary drainage, either alone or in combination with percutaneous drainage $[14,15]$. The availability of EUS has increased our ability to drain these collections transmurally and there are a few case reports of successful EUS-guided transmural drainage of RP $[7,13]$. In the current study, too, all the patients had been successfully treated with various combinations of endoscopic and EUS-guided drainage, with no complications and excellent long-term results. RP can sometimes by located at a distance of more than $1 \mathrm{~cm}$ from the gastric lumen, and placing a plastic transmural stent in these situations could lead to complications of leakage and perforation. Therefore, in these patients we preferred complete single-time EUSguided aspiration of RP, followed by endoscopic transpapillary drainage. We did not use lumen-apposing metal stents (LAMS) in any of our patients, as none of them had significant necrotic debris requiring aggressive transmural drainage. In addition, we had concerns about the flanges of the LAMS impinging upon renal tissue and causing pressure complications.

Its single-center retrospective design and the small sample size were important limitations of our study. Furthermore, there was no single endoscopic drainage procedure performed in all the patients: rather, a combination of various endoscopic and EUS-guided drainage procedures were performed. However, RP are very rare and as far as we can determine from the literature ours is the case series with the largest sample size.

In conclusion, RP usually present with abdominal pain and the majority of patients do not have urinary complaints. EUS can provide important information about the contents of an RP, as well as its distance from the gastrointestinal lumen. Endoscopic drainage, including EUS-guided drainage, is a safe and effective minimally invasive treatment modality for the management of RP. 


\section{Summary Box}

\section{What is already known:}

- Pseudocysts are usually located in the peripancreatic region

- Renal pseudocysts (RP) are rare and there is paucity of literature on their clinical manifestations, radiological findings, and management, including endoscopic as well as endoscopic ultrasound (EUS)-guided drainage of RP

\section{What the new findings are:}

- Renal or vascular complications are rare in patients with RP

- Patients with RP have normal renal function tests with normal urinary amylase values

- Endoscopic drainage, including EUS-guided drainage, is a safe and effective minimally invasive treatment modality for the management of RP

\section{References}

1. Banks PA, Bollen TL, Dervenis C, et al; Acute Pancreatitis Classification Working Group. Classification of acute pancreatitis-2012: revision of the Atlanta classification and definitions by international consensus. Gut 2013;62:102-111.

2. Bhasin DK, Rana SS, Rao C, et al. Clinical presentation, radiological features, and endoscopic management of mediastinal pseudocysts: experience of a decade. Gastrointest Endosc 2012;76:1056-1060.

3. Bhasin DK, Rana SS, Chandail VS, et al. An intra-hepatic pancreatic pseudocyst successfully treated endoscopic transpapillary drainage alone. JOP 2005;6:593-597.
4. Bhasin DK, Rana SS, Udawat HP, Thapa BR, Sinha SK, Nagi B. Management of multiple and large pancreatic pseudocysts by endoscopic transpapillary nasopancreatic drainage alone. Am J Gastroenterol 2006;101:1780-1786.

5. Chhabra P, Rana SS, Sharma V, Bhasin DK. An unusual neck swelling: extension of mediastinal pseudocyst into the neck. Endosc Ultrasound 2017;6:71-72.

6. Rana SS, Sharma R, Chhabra P, Sharma V, Gupta R, Bhasin DK. Endoscopic management of splenic pseudocysts associated with acute and chronic pancreatitis. Ann Gastroenterol 2016;29:373-377.

7. Rana SS, Sharma R, Sharma V, Gupta R. Gastrointestinal: Isolated renal pseudocyst treated with endoscopic transmural drainage. J Gastroenterol Hepatol 2017;32:737.

8. Aswani Y, Anandpara KM, Hira P. Page kidney due to a renal pseudocyst in a setting of pancreatitis. BMJ Case Rep 2015;2015.

9. Baker M, Kopecky K, Wass J. Perirenal pancreatic pseudocysts: diagnostic management. AJR Am J Roentgenol 1983;140:729-732.

10. Upadhye AS, Mathur SK, Bapat RD, et al. Pancreatic pseudocysts simulating renal masses (report of two cases). J Postgrad Med 1986;32:163-165.

11. Tominaga K, Shigoka H, Omuta S, Endo T, Saigusa Y, Maetani I. Left renal pseudocyst associated with alcoholic chronic pancreatitis. BMJ Case Rep 2009;2009.

12. Anderson EM, Betts M. Renal subcapsular pseudocyst: findings onMRI. Magn Reson Imaging 2007;25:736-738.

13. Kimura H, Kamba T, Atsuta T, et al. [A case of renal subcapsular cyst successfully treated with endoscopic ultrasound-guided transgastric drainage of pancreatic pseudocyst]. Hinyokika Kiyo 2012;58:421-424.

14. Bhasin DK, Rana SS, Nanda M, et al. Endoscopic management of pancreatic pseudocysts at atypical locations. Surg Endosc 2010;24:1085-1091.

15. Thandassery RB, Mothilal SKR, Singh SK, et al. Chronic calcific pancreatitis presenting as an isolated left perinephric abscess: a case report and review of the literature. JOP 2011;12:485-488.

16. Matsumoto F, Tohda A, Shimada K, Kubota A. Pancreatic pseudocyst arising from ectopic pancreas and isolated intestinal duplication in mesocolon caused hydronephrosis in a girl with horseshoe kidney. J Pediatr Surg 2005;40:e5-e7.

17. Abrol N, Seth A, Sharma S. Pseudoaneurysm kidney: a rare complication of pseudopancreatic cyst. Urology 2012;79:111-112. 